\title{
Toward More Effective Spectrum Testing and Sharing
}

\author{
Dr. Alan D. Skillicorn \\ The MITRE Corporation \\ Boulder, Colorado
}

\author{
Dr. Michael H. Kelley \\ National Institute of Standards and Technology \\ Boulder, Colorado
}

\author{
Thomas J. Taylor \\ U.S. Department of Defense \\ Washington, D.C. \\ Eric D. Nelson \\ National Telecommunications and Information \\ Administration \\ Institute for Telecommunication Sciences \\ Boulder, Colorado
}

\begin{abstract}
In response to the Presidential Memorandum on Wireless Innovation and the recommendation of the Presidential Council of Advisors on Science and Technology (PCAST), the federal government has begun the process of organizing a National Advanced Spectrum and Communications Test Network (NASCTN) under the auspices of the U.S. Department of Commerce (DOC). The intent of this organization is to provide a single place for information about and access to all federally owned, operated or funded spectrum test facilities. This paper describes the NASCTN effort and the processes that are being developed to support its role as a focal point for spectrum sharing testing in the federal government.
\end{abstract}

Keywords-spectrum; spectrum sharing; testing; NASCTN; CAC, DOC, DOD

\section{INTRODUCTION}

The U.S. President noted in his memoranda on unleashing the wireless broadband revolution [1] and expanding America's leadership in wireless innovation [2] that "expanding the availability of spectrum for innovative and flexible commercial uses... will further promote our Nation's economic development by providing citizens and businesses with greater speed and availability of coverage, encourage further development of cutting edge wireless technologies, applications, and services and help reduce usage charges for households and businesses." It was also noted that "...we must make available even more spectrum and create new avenues for wireless innovation."

Likewise non-federal agencies have noted that re-allocation or sharing between federal and commercial users will be a key component of the strategy to meet growing demands for spectrum [3].

The U.S. Department of Commerce (DOC) has been tasked [2] to facilitate discussions between the federal agencies and non-federal entities with the intent of improving information sharing and collaboration to identify opportunities for the agencies to relinquish, repurpose or share their frequency allocations. As a part of that effort, the DOC is establishing the Center for Advanced Communications (CAC) that provides a single point-of-contact for key interagency issues related to federal spectrum efforts and resources and in so doing creates new functionalities.

One of these new functionalities is the National Advanced Spectrum and Communications Test Network (NASCTN). ${ }^{1}$ NASCTN will take leadership roles in the evaluation of new spectrum sharing technologies. NASCTN will coordinate the use of a national network of test facilities, modeling and simulation (M\&S), and laboratory capabilities, and laboratories across federal, academic, and commercial entities [4]. NASCTN will coordinate the federal efforts of DOC and the Department of Defense (DOD) spectrum sharing. ${ }^{2}$ Additional federal agencies' efforts in this area will be included in the finalized Memorandum of Agreement (MOA).

This paper describes the planned operations of the NASCTN functionality and how it will facilitate the use of available agencies' test facilities, M\&S, and laboratory capabilities in support of spectrum sharing research and engineering. Details are provided on how NASCTN will facilitate the use of existing spectrum sharing capabilities and information. Future process planning and inter-agency coordination issues are presented.

\section{NASCTN OPERATION}

\section{A. Supporting Stakeholders}

NASCTN's operation will provide leadership in the identification and development of spectrum sharing concepts and technology; and act as a trusted agent to support impartial

\footnotetext{
${ }^{1}$ The organization of the CAC and how NASCTN will be hosted are being finalized by DOC. To avoid confusion, NASCTN is represented as a function or capability in this paper.

${ }^{2}$ DOD has elected not to support the NASCTN functionality in a multiagency capacity but to establish a liaison team to NASCTN.
} 
evaluation of spectrum sharing capabilities through an integrated team of federal agencies [4]. It will support federal agencies and non-federal entities as they are developing or implementing spectrum sharing concepts and technology.

These operational goals are in line with both National Telecommunications and Information Administration's (NTIA) emerging strategic plans and the DOD Strategic Plan for the Electromagnetic (EM) Spectrum [5]. Specifically, NASCTN could support the NTIA's three goals of increasing cooperation between federal and non-federal entities; facilitating sharing methods and technologies; and improved information capabilities.

Likewise, NASCTN operations will support the DOD's Strategic Plan for the EM Spectrum [5] by contributing to the development of spectrum-dependent capabilities that have increased spectrum efficiency, flexibility, and adaptability. It will also increase the agility of DOD spectrum operations and sharpen DOD responsiveness to spectrum regulatory and policy changes.

NASCTN's operations in support of federal strategic plans for the spectrum are focused on [4]:

a. Providing the means to facilitate and coordinate work with other federal, academic and industrial users to rapidly and cooperatively facilitate spectrum sharing and co-existence studies;

b. Working together to fairly address the interests and equities of all spectrum stakeholders; and

c. Providing subject matter expert (SME) liaison efforts and support to coordinate and leverage existing national capabilities supporting government, academic, and industry evaluation known to the members to improve and expedite spectrum sharing and co-existence.

NASCTN will support this focus by providing the key functionalities of:

a. Creating a trusted capability for federal, academic, and industry spectrum users to facilitate spectrum sharing studies; optimize access to engineering capabilities; and engage federal, academic, and industry spectrum users in active collaboration;

b. Performing outreach and engagement activities within their respective communities in order to identify spectrum-related evaluation needs, and to disseminate information about the availability and access requirements of engineering capabilities;

c. Protecting information, proprietary, classified, and sensitive, pursuant to applicable agreements, regulations, and statutes while facilitating maximum dissemination of controlled information;

d. Providing a source for spectrum test data, analyses, and reports that can be made available to federal, academic, and industry spectrum users to assist in testing, technology assessments, and other research; and
e. Facilitating coordination, rapid access, and engagement of stakeholder engineering capabilities.

As a part of the NASCTN function to facilitate and coordinate spectrum testing, NASCTN accumulated information may be used by others to improve future research activities. For example, the DOD is working on integrating NASCTN produced information with their Science and Technology spectrum processes.

\section{B. NASCTN Internal and External Relationships}

Maintaining impartiality and providing a trusted relationship amongst the many stakeholders will be critical to an effective and efficient NASCTN functionality. Diverse interests such as commercial development of new wireless technology and operational considerations of federal agencies must be balanced to meet the goals of the Presidential Memorandum [2]. CAC will provide a nationally recognized joint project office that will be the focal point for stakeholder engagement across industry, government, and academia. It will address their research challenges; it will improve access to unique facilities and capabilities, and work with industry and government leaders to prioritize and address the growing need for measurements and standards to support advanced spectrum sharing technology.

CAC will provide the entry point for NASCTN capabilities. The processes used by CAC must be open and unrestricted to enable both federal and non-federal interests. Only through transparent processes can the stakeholder community be effectively engaged.

CAC must maintain direct working relations with the NASCTN engaged federal agencies to clearly define roles and responsibilities. CAC is working to finalize the roles, responsibilities, and other agreements for the initial group of agencies. It is anticipated that the concept of a NASCTN Steering Committee organized around senior representatives from the various federal agencies will provide a key coordination capability.

\section{NASCTN Outreach}

The core of NASCTN's effectiveness will be its ability to reach across all-federal, commercial, and academicspectrum related activities. NASCTN will actively engage the spectrum community rather than wait for specific opportunities.

The outreach as currently envisaged will inform the community of the NASCTN spectrum sharing forum, identify current spectrum sharing activities and plans (both federal and non-federal), and begin to identify testing capabilities across the community.

\section{FACILITATING SPECTRUM SHARING TESTING}

NASCTN will base its efforts to promote spectrum sharing on identifying available and coordinating the use of existing national test facilities and laboratories; expanding the sharing 
of spectrum information; and creating a forum for impartial discussions of the scientific or technical basis for the potentially conflicting interests of federal and non-federal entities.

\section{A. Test Facilities}

Across the federal government and integral to many nonfederal entities there are a number of test facilities, $M \& S$ tools, and laboratory capabilities. These facilities represent significant capabilities, as well as substantial capital investments. Leveraging the unique capabilities of each of these facilities provides an opportunity to reduce cost by avoiding duplication; improve overall test capability by accessing a broad suite of facilities' expertise; and provide unique venues for research and development.

In the near future, NASCTN will serve as a clearing house for federal agencies and non-federal entities to identify test facilities and provide a means for coordinating access to their capabilities. Cataloged facilities will initially be federal capabilities and will eventually expand out to include other facilities such as those in academia and commercial industry. NASCTN is currently collecting pertinent spectrum test information on test capabilities and laboratories. For example, there are twenty three test and training ranges in the DOD that include large air, land, and littoral test areas [6] that could be made available for spectrum testing.

NASCTN will strive to minimize the difficulty in using the available test facilities and laboratories by establishing standard methods for scheduling, planning, and using federal facilities through a common process that includes pre-approved MOAs, facility use agreements (FUAs), and catalogs of capabilities. This support will tend to reduce the time to coordinate test facility use and make that use more economical.

\section{B. Information Sharing}

Spectrum activities including spectrum test planning and spectrum testing generate a large volume of data. Further complicating the ability to locate and use these data is an environment of proprietary, sensitive, and classified interests. NASCTN will operate as a clearing house of spectrum test data and information. By using spectrum information including lessons learned, historic information, and controlled information, spectrum tests should become more effective and efficient. In coordination with the CAC, NASCTN will work to establish procedures to improve information sharing speed and processes.

The lack of availability of information that is proprietary, sensitive or classified has been a major obstacle to effective sharing of spectrum information. NASCTN will work within the federal agencies to develop a more consistent means for the transfer of information. It is also working within DOD to determine a method for the sharing of currently classified spectrum information.

\section{Trusted Agent}

Trusted Agent is the term being used to indicate an unbiased intermediary or group that facilitates access to all, but primarily to sensitive, spectrum related information [7]. The importance of this type of information access was noted during the Commerce Spectrum Management Advisory Committee (CSMAC) [8]. DOC is using the CSMAC effort as a guide for developing a trusted agent role for NASCTN.

The trusted agent role will leverage the information sharing capability of NASCTN to create a more effective dialog and coordination among the federal and non-federal agencies.

\section{NASCTN FURTHER WORK}

\section{A. Roles and Relationship Development}

NASCTN is a new functional capability for DOC and its federal partners. As such, many organizational roles and responsibilities need to be reviewed and clarified. For example, how the NASCTN function will be leveraged to support the Inter-range Instrumentation Group (IRIG) needs to be determined.

To promote the identification, description, and development of the working relationships of NASCTN, DOC is preparing to conduct a Table Top Exercise, a group discussion of a simulated spectrum sharing situation, to explore how the CAC will interact with the NASCTN. The identified organizational relationships and specifics of information required to support the new roles and responsibilities will be identified. It is anticipated that significant progress will be made on this effort this fiscal year.

In addition, as NASCTN identifies potential relationships with non-federal entities, it will work with all stakeholders to identify NASCTN roles and responsibilities to the community.

\section{B. Process Development}

NASCTN's support of spectrum sharing efforts requires efficient processes that meet the requirements of federal agencies and non-federal entities. The NASCTN processes must meet the information content, timeliness, and governance guidelines of DOC and the spectrum community. To accomplish these goals, NASCTN processes will leverage the processes and lessons learned from CSMAC efforts.

Also, to evaluate the efficiency and effectiveness of NASCTN support, Table Top Exercises will be used periodically. Each Table Top Exercise will expand visibility into NASCTN and provide a means for identifying improvements.

NASCTN functionality does not include any spectrum management processes. Current federal spectrum management processes remain intact and will not be affected by NASCTN.

\section{Ten Year Plan}

The future of spectrum sharing has been quantified to a large degree by the NTIA Ten Year Plan $[9,10]$. The spectrum management community has a number of potential sharing opportunities identified in this plan; however, spectrum sharing is a complex problem with competing interests.

The rewards for making additional spectrum available in the bands proposed by the NTIA Ten Year Plan depend on developing reliable means for efficient and effective sharing of 
the spectrum [11]. NASCTN will concentrate its efforts in these areas to improve coordination and collaboration for new and innovative spectrum sharing. Sharing information and establishing trust across the community will significantly improve the likelihood of success in adopting new sharing techniques and technology in these bands.

\section{REFERENCES}

[1] "Unleashing the Wireless Broadband Revolution," Memorandum for the Heads of Executive Departments and Agencies, The White House, Washington D.C., June 28, 2010 http://www.whitehouse.gov/the-pressoffice/presidential-memorandum-unleashing-wireless-broadbandrevolution

[2] "Expanding America's Leadership in Wireless Innovation," Memorandum for the Heads of Executive Departments and Agencies, The White House, Washington D.C., June 14, 2013 http://www.whitehouse.gov/the-press-office/2013/06/14/presidentialmemorandum-expanding-americas-leadership-wireless-innovatio

[3] Coleman Bazelon and Giulia McHenry, "Spectrum Sharing Taxonomy and Economics," The Brattle Group Inc., February 6, 2014 http://www.brattle.com/system/publications/pdfs/000/004/983/original/S pectrum Sharing - Taxonomy and Economics Bazelon McHenry 020614.pdf?1391797552

[4] Jason Boehm, Peter Tenhula, Thomas Taylor, "National Advanced Spectrum and Communications Test Network (NASCTN)," briefing to U.S. Department of Commerce, Washington D.C., June 12, 2013 http://www.nist.gov/director/vcat/upload/Boehm-Adv-Comm.pdf

[5] Ashton B. Carter, Deputy Secretary of Defense, "Electromagnetic Spectrum Strategy," U.S. Department of Defense, September 11, 2013 http://www.defense.gov/news/dodspectrumstrategy.pdf
[6] Derrick Hinton, "RF Spectrum for DOD Training," Briefing to DOD Clearinghouse, Test Resource Management Center, May 2, 2013.

[7] Testimony of Mr. Karl Nebbia Associate Administrator, Office of Spectrum Management National Telecommunications and Information Administration U.S. Department of Commerce, Before the Subcommittee on Communications and Technology Committee on Energy and Commerce United States House of Representatives Hearing on Equipping Carriers and Agencies in the Wireless Era, June 27, 2013

[8] CSMAC Meeting Minutes, National Telecommunications and Information Administration, Commerce Spectrum Management Advisory Committee, March 8, 2013 http://www.ntia.doc.gov/otherpublication/2013/02212013-csmac-meeting-minutes\# Toc350430014

[9] Karl Nebbia, "NTIA Releases Third Interim Progress Report on TenYear Plan to Free Up More Spectrum," Office of Spectrum Management, National Telecommunications and Information Administration, Washington, D.C., December 4, 2012 http://www.ntia.doc.gov/blog/2012/ntia-releases-third-interim-progressreport-ten-year-plan-free-more-spectrum

[10] Gary Locke and Lawrence Strickling, "An Assessment of the Near Term Viability of Accommodating Wireless Broadband Systems in the 1675$1710 \mathrm{MHz}, 1755-1780 \mathrm{MHz}, 3500-3650 \mathrm{MHz}, 4200-4220 \mathrm{MHz}, 4380-$ 4400 MHz Bands," U.S. Department of Commerce, Washington, D.C., October 1, 2010 http://www.ntia.doc.gov/report/2012/ assessmentviability-accommodating-wireless-broadband-1755-1850-mhz-band

[11] Jason Furman, John Holdren,"Making the Most of the Wireless Spectrum," The White House, Office of Science and Technology Policy, Washington, $\quad$ D.C., $\quad$ July 2012 http://www.whitehouse.gov/blog/2012/07/20/making-most-wirelessspectrum 